\title{
Spectroscopic Characterization of Charge-Transfer Complex of Granisteron Hydrochloride and $\sigma$-Acceptor Iodine in Dichloromethane
}

\author{
Mohamed M. Abo-Aly ${ }^{1 *}$, Shabaan A. Abdulla ${ }^{2}$ and Ashraf M. Abdel-Aziz ${ }^{1}$ \\ ${ }^{I}$ Department of Chemistry, Faculty of Science, Ain Shams University, Cairo, Egypt, \\ ${ }^{2}$ NODCAR, Cairo, Egypt
}

\section{A R T I C L E I N F O}

Article history:

Received 20 September 2015

Accepted 03 November 2015

Keywords:

Granisteron $\mathrm{HCl}$ (GRAN);

Charge transfer (CT) complex;

pharmaceutical analysis;

spectrophotometry.

\begin{abstract}
A B S T R A C T
Simple, rapid and sensitive procedure was developed for the analysis of granisteron. $\mathrm{HCl}$ in pure form as well as in their pharmaceutical formulations using CT complex formed between the drug Granisteron hydrochloride and iodine $\left(\mathrm{I}_{2}\right)$ as $\sigma$ - acceptor in dichloromethane. The complex was also investigated spectrophotometrically at equilibrium $(\lambda=365) \mathrm{nm}$ for the iodine complex with different optimized experimental conditions. Job's method indicated the formation of 1:1 complex with iodine. The formation constant and molar absorbivity was determined by Benesi-Hildebrand equation. The validation of analytical procedures of granisteron $\mathrm{HCl}$ and its $\mathrm{CT}$ complex was estimated.
\end{abstract}

\section{Introduction}

Granisetron hydrochloride (GRAN) is a class of $5-\mathrm{HT}_{3}$ antagonists is used to prevent nausea and vomiting caused by cancer chemotherapy and radiation therapy. GRAN works by blocking serotonin; a natural substance in the body that causes nausea and vomiting due to the anesthetics ${ }^{[1,2]}$. Granisetron dosage forms are not yet official in USP and $\mathrm{BP}^{[3]}$.

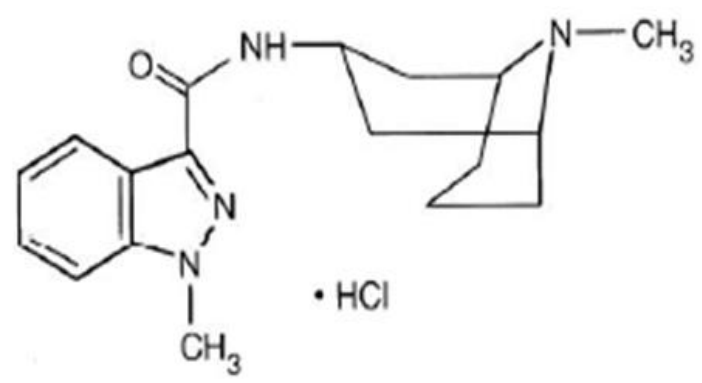

(Structure of Granisteron hydrochloride)

Capacio et al. ${ }^{[4]}$ developed a high performance liquid chromatographic (HPLC) method for the determination of granisteron hydrochloride in guinea pig plasma. Separation was achieved on a spherical silica column and granisteron hydrochloride was detected at $305 \mathrm{~nm}$. The correlation coefficients were reported to be 0.9978 0.9999 and the percent relative standard deviation (\%RSD) was calculated to be about $10 \%$ for inter -day and within-day coefficients of variation $(\% \mathrm{CV})$ ranged from 4.9 to $9.5 \%$ and 3.6 to $7.6 \%$, respectively. Percent errors for within-day test plasma samples were less than

\footnotetext{
* Corresponding author.

E-mail address: aboalymoh@ hotmail.com
}

$8.2 \%$ of the expected concentration for all samples except for $1.125 \mathrm{ng} / \mu \mathrm{L}(14.6 \%)$. The limit of sensitivity was found to be $0.019 \mathrm{ng} / \mu \mathrm{L}$.

Boppana [5] also reported HPLC methods with fluorescence detection for the determination of granisetron in human biological fluids. Pinguet et al. ${ }^{[6]}$ described RP-HPLC method to measure the plasma concentration of granisetron with a mobile phase (a mixture of acetonitrile and sodium phosphate buffer $(\mathrm{pH}$ $4.5)$ in the ratio $v / v$ (15:85). In addition, Bin et al. ${ }^{\text {[7] }}$ established an RP-HPLC method to measure the plasma concentration of granisetron. On the other hand, Nirogi et al. [8] reported two LC-MS/MS methods for the determination of granisetron in human biological fluids. Hewala et al. ${ }^{[9]}$ on the other hand developed a reversed phase HPLC method using photodiode array detection for the simultaneous determination of granisetron hydrochloride, benzyl alcohol, 1-methyl-1H-indazole-3carboxylic acid (the main degradation product of granisetron) and benzaldehyde (the main degradation product of benzyl alcohol) in granisetron injections with Naphazoline hydrochloride as internal standard.

Zaheer and Imran [10] developed UV spectrophotometric methods for the estimation of Granisetron in bulk and tablet dosage form. Prabhakar et al ${ }^{[11]}$ developed and validated UV- spectrophotometric method of Granisetron in bulk and pharmaceutical formulations. Hewale et al. ${ }^{[12]}$ developed the first derivative spectrophotometric determination of Granisetron in presence of hydrolytic products and preservatives and applicable to pharmaceutical 
preparations. The literature survey indicates that there are very few spectrophotometric methods available and hence attempted to develop spectrophtometric method with better sensitivity.

Iodine form molecular complexes with a variety of drugs containing lone pair of electron (non bonding) like oxygen, nitrogen and sulphur which act as electron donors and iodine acts as $\sigma$ - acceptor by forming intense color ${ }^{[13,14]}$.

\section{Experimental procedures \\ Reagents}

Chemically, granisteron hydrochloride (GRAN) is endo$\mathrm{N}$-(9-methyl-9-azabicyclo [3.3.1] non-3-yl)-1-methyl1H-indazole-3-carboxamide hydrochloride with an empirical formula of $\mathrm{C}_{18} \mathrm{H}_{24} \mathrm{~N}_{4} \mathrm{O} . \mathrm{HCl}$ and molecular weight of 348.9 ( 312.4 free base). It is a white to offwhite solid that is readily soluble in water at $20^{\circ} \mathrm{C}$. It is marketed as KYTRIL Tablet (oral administration) containing $1.12 \mathrm{mg}$ of granisetron hydrochloride equivalent to granisetron $1.0 \mathrm{mg}$. The inactive ingredients include hydroxypropyl methylcellulose, lactose, magnesium stearate, microcrystalline cellulose, polyethylene glycol, polysorbate 80, sodium starch glycolate, and titanium dioxide.

- All solvents used were of analytical-reagent grade, $\mathrm{CH}_{2} \mathrm{Cl}_{2}$ from CHD, India. $1 \times 10^{-2} \mathrm{M}$ of Granisteron hydrochloride, GRAN (MW=348.9) stock solution in $\mathrm{CH}_{2} \mathrm{Cl}_{2}$ was prepared, and then diluted to obtain the required concentrations.

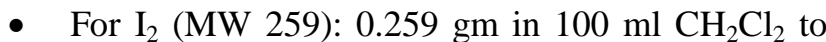
obtain $10^{-2} \mathrm{M}$, more diluted solutions from $2 \times 10^{-5}$ to $1.6 \times 10^{-3} \mathrm{M}$ of drug and acceptor were prepared by dissolving an exact volumes of GRAN and $\mathrm{I}_{2}$ in the same solvent.

\section{Pharmaceutical Formulation Solutions}

- EM-EX $^{\circledR}$ Film-Coated tablet contains $1.12 \mathrm{mg}$ Granisetron Hydrochloride equivalent to Granisetron $1 \mathrm{mg}$ supplied from Amoun pharmaceutical company.

- In case of EM-EX ${ }^{\circledR}$ F.C.T (GRAN) each tablet (0.2 gm) contains $1 \mathrm{mg}$ GRAN, so weigh $3.489 \mathrm{gm}$ of powder in $25 \mathrm{ml}$, sonicate for $10 \mathrm{~min}$ then filter to obtain $2 \times 10^{-3} \mathrm{M}$ of GRAN stock (A), from stock (A) dilute to obtain the required concentrations.

\section{Instrumentation}

UV-visible spectrophotometer, SHIMADZU 1700 (Japan) was used for absorption measurements. Transfer pipettes (5 to 50) ul (GERMANY), VORTEX neolab 720120, Digital balance, Sonicator Elma ${ }^{\circledR}$ Elmasonic S30H (Germany) was used in this study.

\section{Statistical Analysis}

Statistical analysis of the calibration curve parameters (slope, intercept, correlation coefficients and standard deviations) was done using a personal computer with the aid of Microsoft excel software.

\section{Results and discussion}

\section{Spectroscopic determination of GRAN}

\section{Identification of band maxima}

Standard solution of drug $1 \times 10^{-2} \mathrm{M}(1 \mathrm{ml})$ was mixed with $1 \mathrm{ml}$ of $1 \times 10^{-2} \mathrm{M}$ of iodine into $10 \mathrm{ml}$ volumetric flask and was completed the volume with dichloromethane, brown color was obtained indicated the formation of charge transfer complex (CT) between drug and iodine. The CT complex was measured in range 200 to $800 \mathrm{~nm}$ and displays a new band with maximum wavelength at $365 \mathrm{~nm}$ Fig (1).

\section{Effect of concentration of acceptor}

Into a series of $10 \mathrm{ml}$ volumetric flask different volume of $1 \times 10^{-3} \mathrm{M}$ of iodine solution ranged from 0.25 to $5 \mathrm{ml}$ was transferred and then add $1 \mathrm{ml}$ of $1 \times 10^{-3} \mathrm{M}$ of drug vortex for $30 \mathrm{sec}$, completed the volume with dichloromethane to $10 \mathrm{ml}$, with waiting for 30 minutes before measuring the absorbance, Fig (2). The Fig. shows that a 1:1 complex is formed at equilibrium.

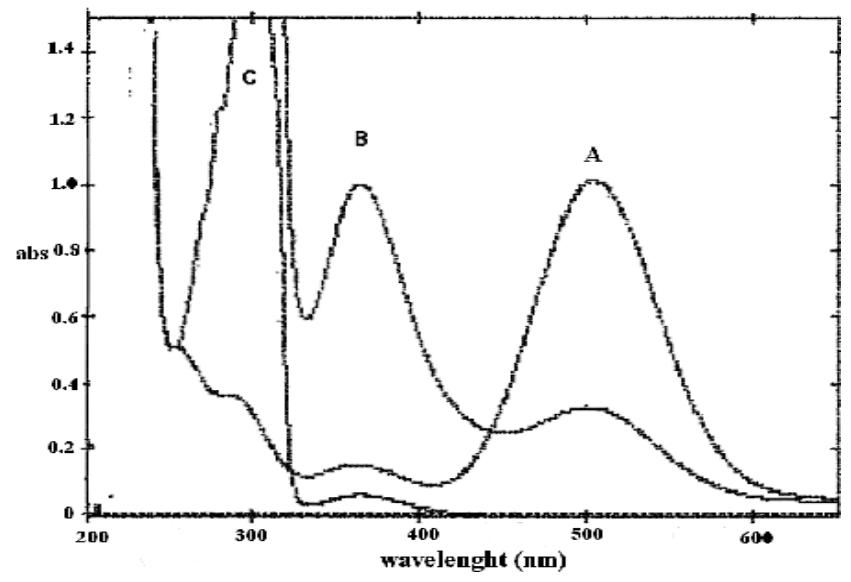

Fig 1: UV-vis spectra of (A) $I_{2}, 1 X 10^{-3} \mathrm{M}$ solution in dichloromethane (B) complex (GRAN-I $)_{2}$ and (C) GRAN.

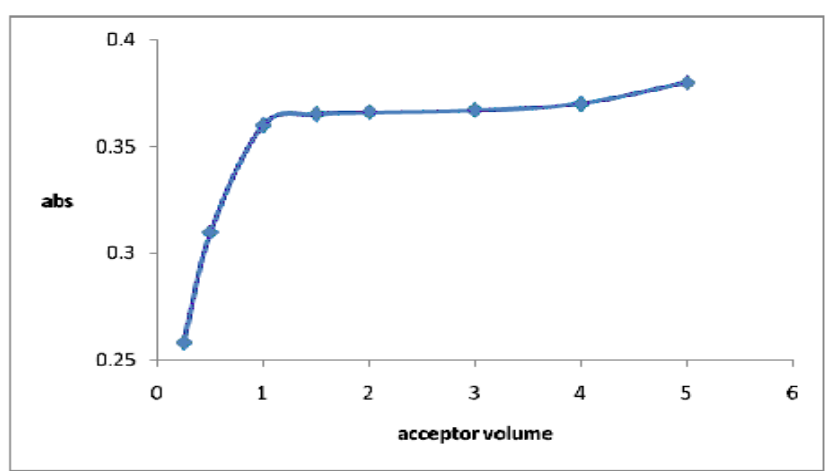

Fig 2: Plot of $\mathrm{I}_{2}$ conc vs. absorbance of GRAN- $\mathrm{I}_{2}$ complex in dichloromethane at room temperature.

\section{Effect of solvent on the formation of charge transfer} complex

The effect of solvent on the formation of charge transfer complex was studied using different solvents like acetonitrile, ethanol, methanol, benzene, acetone, 
toluene, chloroform and dichloromethane. Benzene, acetone, methanol and ethanol were unsuitable due to formation of CT complexes with iodine and limit of solubility in acetonitrile. Dichloromethane afforded maximum sensitivity when compared with other solvents and was used in this study.

Effect of time on the stability of the formed charge transfer complex

The effect of time was studied by recording the absorbance at $365 \mathrm{~nm}$ at different time intervals from 5 to $45 \mathrm{~min}$ at room temperature as illustrated in Fig. (3), 30 minutes were used as the best time which gives maximum absorbance at equilibrium.

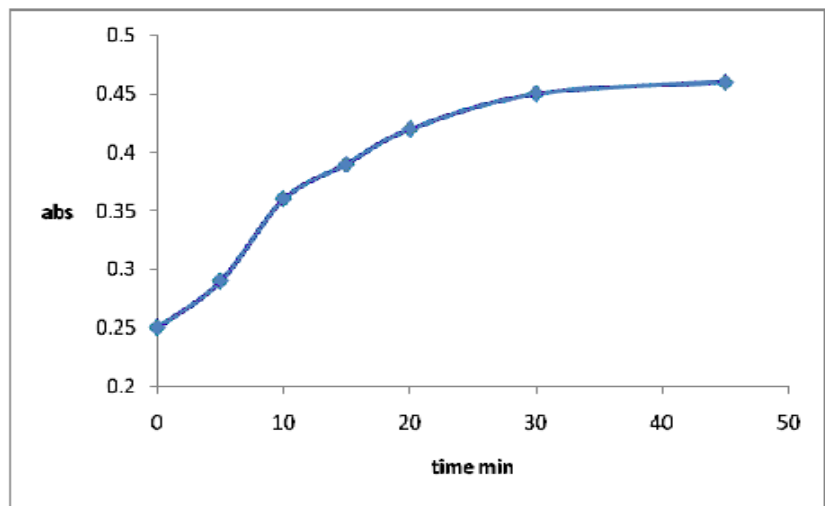

Fig 3: Plot of time vs. absorbance of GRAN- $\mathrm{I}_{2}$ complex at room temperature.

\section{Determination of the stoichiometry of reaction}

Job's method of continuous variation ${ }^{[15]}$ was applied in order to ascertain the stoichiometry of the reaction between drug and iodine. Solution of $1 \times 10^{-3} \mathrm{M}$ of both drug and iodine were used. A series of solutions were prepared in which the total volume of the drug and iodine was kept at $10 \mathrm{ml}$. The reagents were mixed in various preparation allowed to stand at $25^{\mathrm{O}} \mathrm{C}$ for 30 minutes and then diluted to volume with $10 \mathrm{ml}$ dichloromethane. The absorbance was measured at 365 nm. Results revealed 1:1 complexation ratio under optimum conditions, Fig. (4).

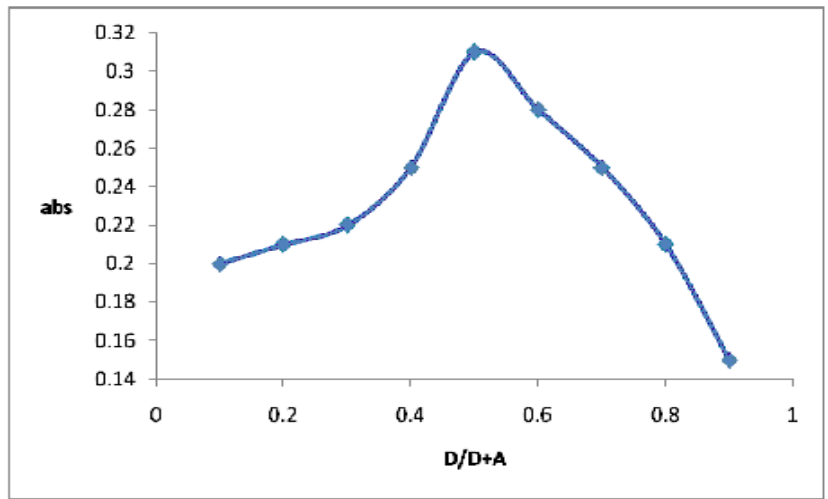

Fig 4: Plot of molar ratio $(\mathrm{D} / \mathrm{D}+\mathrm{A})$ vs absorbance of GRAN-I $\mathrm{I}_{2}$ complex.
The Benesi-Hildebrand Method for Determination of $K_{f}$ for DA association and $\varepsilon$ Values for DA CT absorption

The Benesi-Hildebrand analysis involves the measurement of the CT complex absorbance as a function of varied concentration of acceptor [A] when $[\mathrm{A}]>>[\mathrm{D}]^{[16]}$, where $[\mathrm{D}]$ is the concentration of donor.

$[\mathrm{D}]_{\mathrm{o}} / \mathrm{Abs}=(1 /[\mathrm{A}])\left(1 / \mathrm{K}_{\mathrm{f}} \varepsilon\right)+1 / \varepsilon$

A plot of $1 /[\mathrm{A}]_{\mathrm{o}}$ vs $[\mathrm{D}]_{\mathrm{o}} /$ Abs gives $(\varepsilon)$ from the intercept $=1 / \varepsilon$ and formation constant $\left(K_{f}\right)$ from the slope $=\left(1 / K_{f}\right.$ $\varepsilon)$.

Which DA donor acceptor complex.

$\varepsilon$ molar absorbivity.

$\mathrm{K}_{\mathrm{f}}$ formation constant.

Association constant and free energy

To determine $\mathrm{K}_{\mathrm{f}}, 1 \times 10^{-2} \mathrm{M}$ and $1 \times 10^{-3} \mathrm{M}$ solutions of GRAN and of iodine were prepared, respectively. $2 \mathrm{ml}$ from the stock of GRAN was taken, and from iodine; different solution volumes from 0.05 to $0.5 \mathrm{ml}$, were taken and then completed to $10 \mathrm{ml}$ with dichloromethane and the absorbance for the CT complex at $365 \mathrm{~nm}$, was measured Fig. (5).

According to equation (1), plot of [D] $]_{\mathrm{o}} /$ absorbance against $\left(1 /\left[\mathrm{A}_{\mathrm{o}}\right]\right)$ gives a straight line fitted with equation: $\mathrm{y}=0.000001 \mathrm{x}+0.000922$. The slope equals to $\left(1 / \varepsilon \mathrm{K}_{\mathrm{f}}\right)=$ $1 \times 10^{-6}$, the intercept equals to $1 / \varepsilon$ with $\varepsilon=1.084 \times 10^{3}$, So $\mathrm{K}_{\mathrm{f}}=1 /$ slope $\mathrm{x} \varepsilon=9.22 \times 10^{2}$ and the free energy of the complex, $\Delta \mathrm{G}_{\mathrm{O}}=-\mathrm{RT} \ln \mathrm{K}=-2.303 \mathrm{RT} \log \mathrm{K}=-2.303$ x $8.314 \times 298 \times \log \left(9.22 \times 10^{2}\right)=-16.916 \mathrm{~kJ} \cdot \mathrm{mol}^{-1}$.

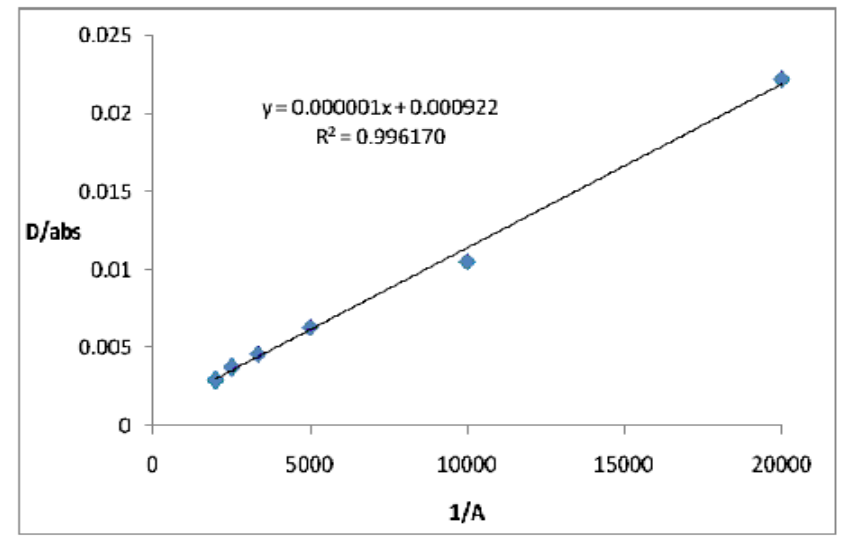

Fig 5: Plot of 1/A versus D/absorbance of GRAN- $I_{2}$ complex.

\section{Analytical investigation}

\section{Calibration curve of GRAN-I}

The calibration curve was constructed in the range $2 \times 10$

${ }^{5}-1.6 \times 10^{-3} \mathrm{M}$ by preparing $2 \times 10^{-3} \mathrm{M}$ stock solution of GRAN and $1 \times 10^{-2} \mathrm{M}$ of iodine. The calibration points are given in Table (1).

By adoption the optimum conditions, the calibration curve is constructed with iodine at $365 \mathrm{~nm}$. The relationship between the absorbance of the CT complex and concentration was shown in Fig (6). Linear relationship was obtained in the range $2 \times 10^{-5}-1.6 \times 10^{-3}$ M, Table (1). 

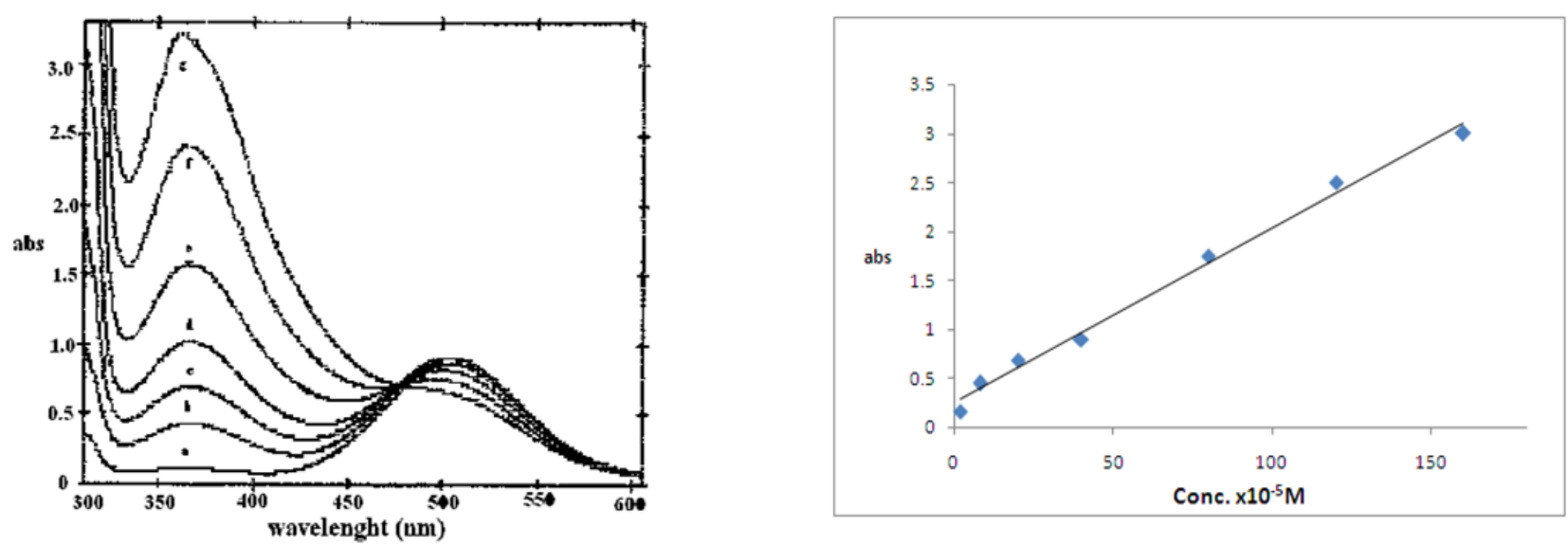

Fig 6: Calibration of GRAN- $\mathrm{I}_{2}$ complex using solvent as blank. [GRAN] $\times 10^{-5},\left[\mathrm{I}_{2}\right]=1 \times 10^{-3} \mathrm{M}$.

Table 1: Concentration range of GRAN- $\mathrm{I}_{2}$.

\begin{tabular}{c|c}
\hline \multicolumn{2}{c}{ GRAN-I } \\
\hline $\begin{array}{c}\text { Conc. of drug } \\
\mathbf{X 1 0}^{-5} \mathbf{M}\end{array}$ & abs \\
\hline 2 & 0.16 \\
8 & 0.45 \\
20 & 0.68 \\
40 & 0.90 \\
80 & 1.75 \\
120 & 2.50 \\
160 & 3.00 \\
\hline
\end{tabular}

Table 2: Assay of GRAN-I $\mathrm{I}_{2}$ using proposed spectroscopic technique.

\begin{tabular}{|c|c|c|c|c|c|}
\hline $\begin{array}{c}\text { [Taken], } \\
(\mathrm{M})\end{array}$ & $\begin{array}{l}\text { [Found], } \\
(\mathbf{M})\end{array}$ & mean & $\mathbf{R} \%$ & SD & $\%$ RSD \\
\hline $4.0 \times 10^{-5}$ & $\begin{array}{l}4.008 \times 10^{-5} \\
4.10 \times 10^{-5} \\
3.99 \times 10^{-5} \\
3.90 \times 10^{-5}\end{array}$ & $3.99 \times 10^{-5}$ & 99.74 & 0.082 & 0.081 \\
\hline $8.0 \times 10^{-5}$ & $\begin{array}{l}8.02 \times 10^{-5} \\
8.05 \times 10^{-5} \\
8.10 \times 10^{-5} \\
7.99 \times 10^{-5}\end{array}$ & $8.04 \times 10^{-4}$ & 100.5 & 0.046 & 0.046 \\
\hline $8.0 \times 10^{-4}$ & $\begin{array}{c}8.01 \times 10^{-4} \\
8.02 \times 10^{-4} \\
7.9 \times 10^{-4} \\
7.95 \times 10^{-4}\end{array}$ & $7.9710^{-4}$ & 99.62 & 0.055 & 0.054 \\
\hline
\end{tabular}




\section{Validation of analytical procedure}

Validation of the present proposed procedures for assay of GRAN-I ${ }_{2}$ was examined via repeatability, recovery, selectivity, within day and between day calibrations.

The obtained results were confirmed the reliability of the proposed procedure for the trace quantitation of bulk GRAN. Repeatability of results of the procedure was examined by performing four replicates measurements for $4 \times 10^{-5}, 8 \times 10^{-5}$ and $8.0 \times 10^{-4} \mathrm{M}$ of GRAN-I $\mathrm{I}_{2}$ and it gives mean percentage recoveries 99.74, 100.5 and $99.62 \%$, respectively, Table 2.

The selectivity of the described procedures was tested by analysis of $4 \times 10^{-5}, 8 \times 10^{-5}$ and $8 \times 10^{-4} \mathrm{M}$ standard granisteron hydrochloride and a standard formulation $\left(\mathrm{EM}^{\mathrm{E}} \mathrm{EX}^{\circledR}\right)$ which gives recoveries $97.5,100.3$ and 99.3, respectively, Table (3). No significant differences in the recoveries or the relative standard deviations were obtained in the absence and presence of excipients. Thus, the proposed procedure can be considered selective. LOD and LOQ ${ }^{[17]}$ were calculated according to equations (2), (3) as given in Table (4).

LOD $=3.3 \mathrm{~S} . \mathrm{D} / \mathrm{b}$

$\mathrm{LOQ}=10 \mathrm{~S} . \mathrm{D} / \mathrm{b}$

Where S.D is the standard deviation and $b$ is the slope of the calibration curve.

The robustness of the proposed procedure was examined by studying the effect of variation of some of the neck procedural conditions such as time $(15-30) \mathrm{min}$, volume of acceptor $(0.8,1.2 \mathrm{ml})$. The mean percentage recoveries based on four replicate measurements were not significantly affected and consequently the optimized procedure was reliable for assay of GRAN and could be considered robust Table (5).

Table 3: Assay of bulk and formulation EM-EX® film-coated tablet.

\begin{tabular}{|c|c|c|c|c|c|}
\hline $\begin{array}{c}\text { [standard] } \\
\text { (M) }\end{array}$ & $\begin{array}{c}\text { [Found], } \\
\text { Formulation } \\
\text { (M) }\end{array}$ & Conc. & Mean & S.D & RSD \\
\hline $4 \times 10^{-5}$ & $\begin{array}{c}4.01 \times 10^{-5} \\
4.02 \times 10^{-5} \\
3.98 \times 10^{-5} \\
3.6 \times 10^{-5}\end{array}$ & $3.9 \times 10^{-5}$ & 97.5 & 0.2 & 0.19 \\
\hline $8 \times 10^{-5}$ & $\begin{array}{l}8.03 \times 10^{-5} \\
8.01 \times 10^{-5} \\
8.10 \times 10^{-5} \\
7.98 \times 10^{-5}\end{array}$ & $8.03 \times 10^{-4}$ & 100.3 & 0.05 & 0.05 \\
\hline $8 \times 10^{-4}$ & $\begin{array}{c}8.01 \times 10^{-4} \\
8.12 \times 10^{-4} \\
7.9 \times 10^{-4} \\
7.8 \times 10^{-4}\end{array}$ & $7.95 \times 10^{-4}$ & 99.3 & 0.13 & 0.12 \\
\hline
\end{tabular}

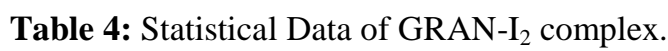

\begin{tabular}{c|c}
\hline Statistical Parameters & GRAN-I $_{2}$ \\
\hline Correlation Coefficient & 0.992 \\
\hline $\begin{array}{c}\text { Regression equation } \\
\text { Y=ax+b }\end{array}$ & $\mathrm{y}=0.017 \mathrm{x}+0.252$ \\
\hline Concentration Range (M) & $2 \times 10^{-5}-1.6 \times 10^{-3}$ \\
\hline S.D of blank & 0.017 \\
\hline LOD (M) & $3.3 \times 10^{-5}$ \\
\hline LOQ (M) & $1.0 \times 10^{-4}$ \\
\hline
\end{tabular}


Table 5: Results of robustness of GRAN $-\mathrm{I}_{2}$ complex.

\begin{tabular}{l|l}
\hline Robustness conditions & Recovery \\
\hline Iodine volume $0.8 \mathrm{ml}$ & $99 \%$ \\
Iodine volume $1.2 \mathrm{ml}$ & $98 \%$ \\
Equilibrium time $15 \mathrm{~min}$ & 100.2 \\
Equilibrium time $15 \mathrm{~min}$ & 100.5 \\
\hline
\end{tabular}

\section{Conclusion}

Simple, sensitive, extraction-free, rapid and costeffective spectrophotometric method based on charge transfer complex formation reaction was developed and validated for the determination of GRAN drug. The reagents used in the proposed method are cheap, available and the procedure does not involve any critical reaction conditions or tedious sample preparation. The method is more selective than many of the reported spectrophotometric methods which gives higher ranges 5-25 ug/ml Venkata et $\boldsymbol{a l} .{ }^{[18]}$ and employs a higher wavelength to measure absorbance readings where the errors due to inactive ingredients are minimized to a large extent. The method is free from interferences from the common excipients and other basic substances present, which don't form CT complex.

The statistical parameters and the recovery data reveal good accuracy and precision of the method which can be used as general method for the determination of these types of drugs in pure powder and dosage forms.

\section{References}

1) Brunton, L. L., Lazo, J. S. and Parker, K. L. (2005). Goodman and Gilman's The Pharmacological Basis of Therapeutics, $11^{\text {th }}$ ed., McGraw-Hill Medical Publishing Division, New York.

2) Aapro, M. (2004). Granisetron: An Update on its Clinical Use in the Management of Nausea and Vomiting. The Oncologist, 9: 673-686.

3) The British Pharmacopeia, (2008). British Pharmacopoeial Commission: London, UK.

4) Capacio, B.R., Byers, C.E., Jackson, T.K. and Matthews, R. (1993). An HPLC method for the determination of granisetron in guinea pig plasma. $\mathbf{J}$ Anal Toxicol., 17(3), 151-155.

5) Boppana, V. K. J. (1995). Simultaneous determination of granisetron and its 7-hydroxy metabolite in human plasma by reversed-phase high-performance liquid chromatography utilizing fluorescence and electrochemical detection. Chromatogr: A, 692: 195-202.

6) Pinguet, F., Bressoll, F. C., Martel, P., Salabert, D. and Astro, C. (1996). RP HPLC method to measure the plasma concentration of granisetron using fluorescence detector. Journal of chromatography B; Biomedical sciences and applications, 675: 99-105.
7) Bin, R., Bin, D., Shu-Xia, L. I., Lianhu, J., Hailing, H. and Lei, T. (2003). Measurement of granisteron in plasma using RP-HPLC. Chinese Journal of Hospital Pharmacy, 1: 25-26

8) Nirogi, R. V. S., Kandikere, V. N., Shukla, M., Mudigonda, K., Maurya, S., and Boosi, R. (2006). Quantification of granisetron in human plasma by liquid chromatography coupled to electrospray tandem mass spectrometry. Biomed. Chromatogr., 20: $888-897$.

9) Hewala, I., El-Fatatre, H., Emam, E. and Mubrouk, M. (2010). Development and application of a validated stability-indicating HPLC method for simultaneous determination of granisetron hydrochloride, benzyl alcohol and their main degradation products in parenteral dosage forms. Talanta. 82(1), 184-195.

10) Zahid, Z. and Sayad, I. (2011). UV spectrophotometric developed method for the estimation of Granisetron in bulk and tablet dosage form. Pharm Ana \& Qual Assur, 7: 15.

11) Panzade, P., Puranik, P., Mogal, V. and Ayursanthi, M. (2010). New spectrophotometric developed method for the determination of Granisetron in bulk and tablet form. AJRC, 3(3): 634-636.

12) Hewale, I., Bedair, M. M. and Shausha, S. M. (2012). Drug Testing and Analysis.

13) Mulliken, R.S., and Person W.R. (1969). Molecular complexes John Wiley and sons, New York, pp 156-160.

14) Foster, R. (1969). Organic charge transfer complex (Academic press London), pp 33-93.

15) Job, P. (1925). Camp Rend (Paris), 180: 928.

16) Benesi, H. A. and Hildebrand, J. H. (1949). A Spectrophotometric Investigation of the Interaction of Iodine with Aromatic Hydrocarbons. J. Am. Chem. Soc., 71: 2703.

17) Miller, J.C. and Miller, J.N. (1993). "Statistics for Analytical Chemistry" $3^{\text {rd }}$ Ed., Ellis Horwood Serie. Prentice Hall, New York, pp. 119.

18) Rao, V., Ramu, S. V., Malleswara, G., Rao, N. V. N. and Rambabu, C. (2012). Development of simple and Sensitive visible spectrophotometric methods for the determination of Granisetron Hydrochloride in pure and pharmaceutical formulations. International Journal of PharmTech Research, 4(4): 1508-1512. 